mean hourly heart rate curve before awakening clearly indicates that beta adrenoreceptor blockade is still present. Several studies from this laboratory have shown that this part of the circadian curve is reduced by alpha adrenoreceptor blockers, ${ }^{15}$ which again suggests that the alpha receptor is important at this time of the day.

Thiazide diuretics exert their antihypertensive effect by virtue of direct arteriolar vasodilatation, and we have shown that the net effect on the circadian curve is an overall lowering of values without any change in the shape of the curve. ${ }^{12}$ The addition of a diuretic to a beta adrenoreceptor blocking drug would be expected to enhance the daytime effect and also lower the night time and early morning curve. This study shows that this is exactly what happens and suggests that the combination of a beta adrenoreceptor blocker and a diuretic is not only very effective but very desirable.

During isometric exercise metoprolol and placebo caused a reduction in the absolute pressure, and there was an even greater reduction when metoprolol was combined with chlorthalidone. Earlier studies with other beta adrenoceptor blocking agents have shown appreciable reductions of the blood pressure at low grades of dynamic work but not during higher grades. ${ }^{2}$ The results of our study confirm this finding; however, the importance of this is difficult to assess because few patients could achieve the higher workloads.

We have shown that in patients with mild to moderate hypertension slow release metoprolol and placebo produced an appreciable fall in the blood pressure during the daytime only. Metoprolol and chlorthalidone produced an appreciably greater fall in blood pressure which was maintained over the full 24 hours. Both regimens led to a reduction in the response of the blood pressure to isometric and dynamic bicycle exercise. We conclude that adding thiazide diuretics to beta adrenoreceptor blocking drugs enhances the effect and duration of control of blood pressure.

\section{References}

1 Koch-Weser J. Drug therapy; metoprolol. $N$ Engl $\mathcal{f}$ Med 1979;301: 698-703.

${ }^{2}$ Mann S, Millar-Craig MW, Altman DG, Melville DI, Raftery EB. The effects of metoprolol on ambulatory blood pressure. Clin Sci 1979;57, suppl:375-7.

${ }^{3}$ Jaattela A, Pyorala K. A controlled study on the antihypertensive effect of a new beta-adrenergic receptor blocking drug, metoprolol, in combination with chlorthalidone. Br f Clin Pharmacol 1976;3:655-60.

4 Porter A. Drug defaulting in a general practice. Br Med f 1969;i :218-22.

${ }^{5}$ Karlberg B, Nilsson O, Tolagen K, Nitelius E, Waern U. Once daily metoprolol in primary hypertension. Clin Pharmacol Ther $25: 399-407$.

${ }^{6}$ Millar-Craig MW, Hawes D, Whittington J. New system for recording ambulatory blood pressure in man. Med Biol Eng Comput 1978;16: 727-31.

' Gould BA, Mann S, Kieso H, Bala Subramanian V, Raftery EB. The 24 hour ambulatory blood pressure profile with verapamil. Circulation $1982 ; 65: 22-7$.

${ }^{8}$ Cashmann PMM, Stott FD, Millar-Craig MW. Hybrid system for fast data reduction on long term blood pressure recordings. Med Biol Eng Comput $1979 ; 17: 629-35$.

${ }^{9}$ Millar-Craig MW, Bishop C, Raftery EB. Circadian variation of blood pressure. Lancet 1978; i:795-7.

${ }^{10}$ Hills M, Armitage P. The two period cross over clinical trial. $\mathrm{Br} f \mathrm{Clin}$ Pharmacol $1979 ; 8: 7-20$

$"$ Floras J, Fox P, Hassan MO, Jones JV, Sleight P, Turner K. Assessment of the antihypertensive effect of atenolol using 24 hour ambulatory monitoring of the blood pressure. Clin Sci 1979;57, suppl 5:387-9.

12 Raftery EB, Melville DI, Gould B, Mann S, Whittington JR. A study of the antihypertensive actions of xipamide using ambulatory intra-arterial monitoring. Br 7 Clin Pharmacol $1981 ; 12: 381-5$.

${ }^{13}$ Mann S, Millar-Craig MW, Bala Subramanian V, Raftery EB. Once daily beta-blockade in hypertension: an ambulatory assessment. $\mathrm{Br} f \mathrm{Clin}$ Pharmacol $1981 ; 12: 223-8$.

14 Millar-Craig MW, Kenny D, Mann S, Bala Subramanian V, Raftery EB. Effect of once daily atenolol on ambulatory blood pressure. $\mathrm{Br} \mathrm{Med} \mathcal{F}$ $1979 ; \mathrm{i}: 237-9$

15 Gould BA, Mann S, Davies AB, Altman DG, Raftery EB. Alpha-adrenoreceptor blockade with Indoramin in hypertension. $\mathcal{f}$ Cardiovasc Pharmacol 1983;5:343-8.

(Accepted 14 fune 1983)

\title{
Clinical importance of reversibility in primary goitrous hypothyroidism
}

\author{
MOTOTAKA YOSHINARI, KEN OKAMURA, TAKASHI TOKUYAMA, AKIYO SHIROOZU, \\ TOSHIRO NAKASHIMA, KENJIRO INOUE, TERUO OMAE
}

\begin{abstract}
Twenty seven hypothyroid patients with a serum concentration of thyroid stimulating hormone (TSH) of over $40 \mathrm{mU} / 1$ were followed up for three to 20 weeks without replacement therapy. The serum thyroid hormone concentrations increased with a dramatic decrease in serum TSH values in 14 patients (reversible group) but
\end{abstract}

\footnotetext{
Second Department of Internal Medicine, Faculty of Medicine

Kyushu University, Fukuoka, Japan

MOTOTAKA YOSHINARI, MD, research associate

KEN OKAMURA, MD, staff

TAKASHI TOKUYAMA, MD, research associate

AKIYO SHIROOZU, MD, staff

TOSHIRO NAKASHIMA, MD, senior instructor

KENJIRO INOUE, MD, associate professor

TERUO OMAE, MD, professor
}

Correspondence to: Dr Ken Okamura, Second Department of Internal Medicine, Faculty of Medicine, Kyushu University 60, 3-1-1, Maidashi, Higashi-ku, Fukuoka City 812, Japan. there was no significant change in the other 13 (irreversible group). Fourteen out of 19 patients with goitre but none of the eight patients without goitre belonged to the reversible group. All of the 11 patients with a high uptake of iodide by the thyroid, three of the six with a normal uptake, and none of the 10 with a low uptake belonged to the reversible group.

These observations indicate that patients with goitrous hypothyroidism with a preserved thyroid uptake of iodide are likely to become euthyroid spontaneously without replacement therapy.

\section{Introduction}

Transient hypothyroidism occurs after delivery ${ }^{1}$ " or after ingestion of excess iodide. ${ }^{3}{ }^{4}$ Hashimoto's thyroiditis is thought to be responsible for this phenomenon. Rallison et al observed spontaneous resolution of hypothyroidism owing to chronic thyroiditis in a large number of school children. ${ }^{5}$ Spontaneous remission of primary hypothyroidism has also been reported 
sporadically in adults, ${ }^{6}$ \& but standard textbooks recommend that hypothyroid patients should be given thyroid hormone replacement therapy. ${ }^{9}{ }^{12}$ We therefore studied the reversibility of the condition in patients with overt primary hypothyroidism before they started lifelong replacement therapy.

\section{Patients and methods}

Thirty three Japanese patients with overt primary hypothyroidism were seen in the second department of internal medicine at Kyushu University Hospital from 1977 to 1982. None of the patients had had thyroid surgery or irradiation to the neck or gave a history of subacute thyroiditis. The basal serum concentration of thyroid stimulating hormone (TSH) was over $40 \mathrm{mU} / 1$ and the patients gave an exaggerated response to TSH releasing hormone. Two patients dropped out within two weeks, and four had postpartum hypothyroidism. These six were excluded from the study. The remaining 27 patients were four men and 23 women (who had not been pregnant within five years of their attendance at our hospital). They were asked to avoid foods rich in iodine, and we observed them for three to 15 weeks before starting replacement therapy.

Thyroid function tests included measurements by radioimmunoassay of serum total thyroxine (T4), triiodothyronine (T3), and TSH. Twenty four hour uptake of ${ }^{131}$ I by the thyroid (normal value 10 to $35 \%$ ) was determined after iodine rich foods had been restricted for more than one week, except in one patient, in whom 30 minute uptake of ${ }^{99 \mathrm{~m} T c}$ was measured. Thyroid autoantibodies to thyroglobulin and microsomes (normally negative) were measured by the tanned sheep erythrocyte haemagglutination technique using commercial kits (Fujizoki Pharmaceutical Co Ltd, Tokyo). In seven cases the perchlorate discharge test was performed.

Statistical analyses were performed with Student's $t$ test, and the $\chi^{2}$ test.

\section{Results}

Serum concentrations of T3, T4, and TSH were restored towards normal in 14 of the 27 patients (reversible group) (fig 1). The increase in serum thyroid hormone concentrations began to occur after two weeks, and 10 patients became euthyroid within three months. In four others serum concentrations of $\mathrm{T} 3$ and $\mathrm{T} 4$ returned to normal but that of TSH remained over $10 \mathrm{mU} / \mathrm{l}$, and the supplementary treatment with thyroid hormone was started. In the remaining 13 patients (irreversible group) no significant changes in serum thyroid hormone values were found and replacement therapy was started after 3-15 weeks of observation.

There was no difference in age, sex, or observation periods between the reversible and irreversible groups (table I). The serum concentrations of T3 and T4 in the reversible group at the first visit were somewhat higher than those in the irreversible group ( $<0.05$ for both),

Clinical profile of 27 patients with reversible and irreversible primary hypothyroidism. Values are means $(S D)$

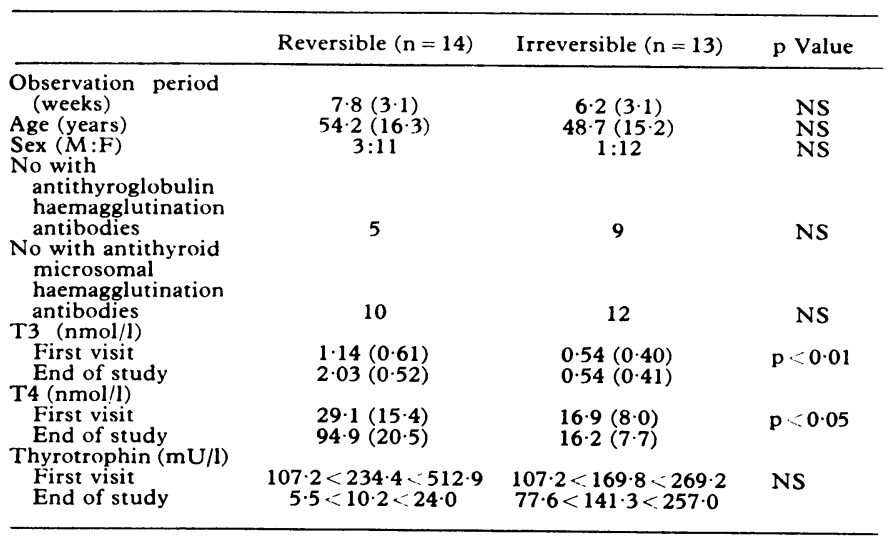

* A log transformation was applied for the statistical calculation of TSH (mean - SD

NS $=$ Not significant.

Conversion: SI to traditional units-T3: $1 \mathrm{nmol} / 1 \approx 0.65 \mathrm{ng} / \mathrm{ml} . \mathrm{T} 4: 1 \mathrm{nmol} / \mathrm{l} \approx$ $0.078 \mu \mathrm{g} / 100 \mathrm{ml}$ although the serum concentration of $\mathrm{TSH}$ and the percentage of patients with positive circulating autoantibodies in the reversible group did not differ from those in the irreversible group. A goitre was palpable in all of the reversible group but in only five of the irreversible group.

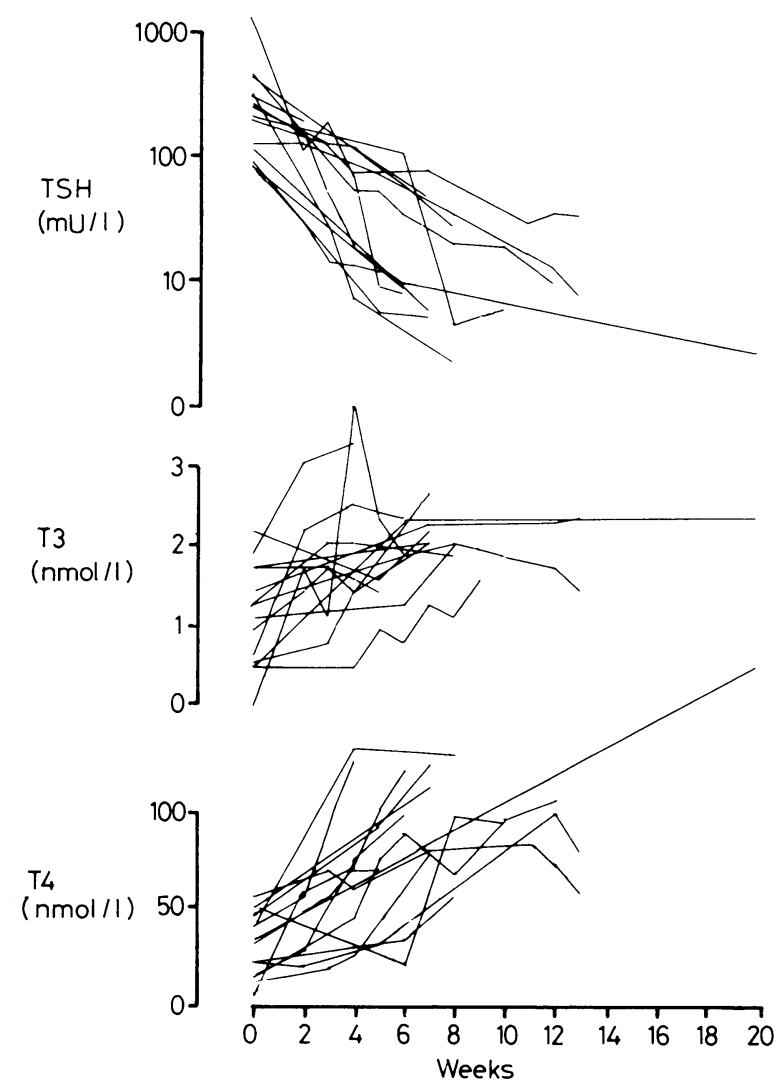

FIG 1 -Serum concentrations of T3, T4, and TSH in subjects with reversible primary hypothyroidism. Normal values for $\mathrm{T} 3, \mathrm{~T} 4$, and $\mathrm{TSH}$ are $1 \cdot 4-3 \cdot 2 \mathrm{nmol} / 1(0 \cdot 9-2 \cdot 1 \mathrm{ng} / \mathrm{ml}), 58-161 \mathrm{nmol} / 1(4 \cdot 5-12 \cdot 6 \mu \mathrm{g} / 100 \mathrm{ml})$ and $10 \mathrm{mU} / \mathrm{l}$, respectively.

Conversion: SI to traditional units-T3:1 $\mathrm{nmol} / 1 \approx 0.65 \mathrm{ng} / \mathrm{ml}$. T4 $1 \mathrm{nmol} / 1 \approx 0.078 \mu \mathrm{g} / 100 \mathrm{ml}$.

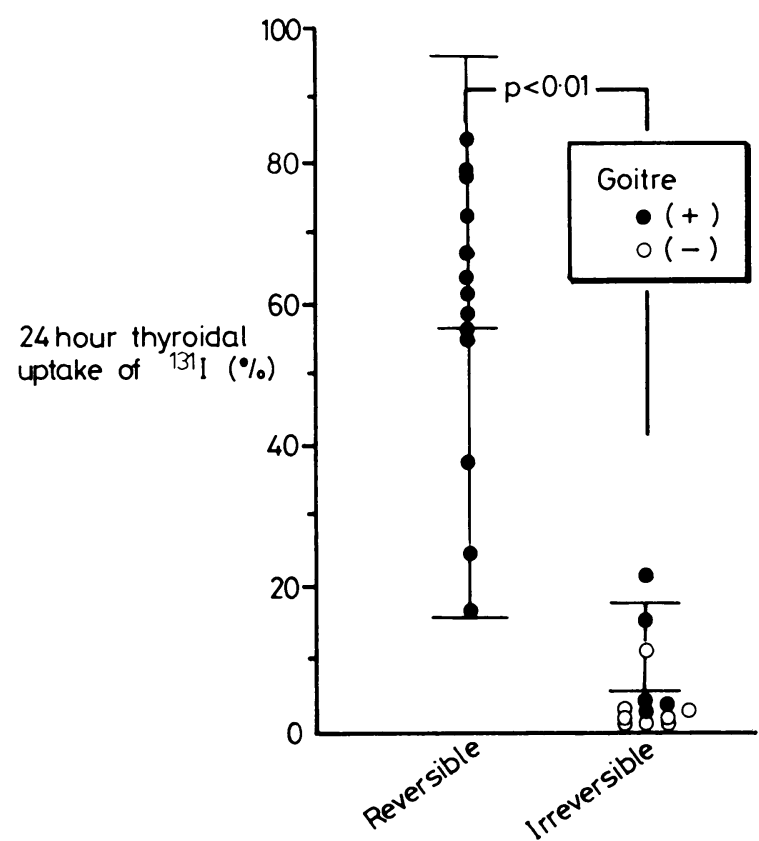

FIG 2-Twenty four hour thyroidal uptake of ${ }^{131} \mathrm{I}$ in patients with primary hypothyroidism. Values were significantly higher in the reversible group $(p<0 \cdot 01)$. Horizontal bars represent mean and SD. 
Twenty four hour uptake of ${ }^{131} \mathrm{I}$ in the reversible group was significantly higher than that in the irreversible group (56.4 (SD 20.3) \% $v$ $5.43(6.22) \%, \mathrm{p}<0.01$; fig 2$)$. In all 11 of the patients with a high uptake $(27.6 \%$ uptake of $99 \mathrm{~m} \mathrm{Tc}$ in one case) and in three out of six with a normal uptake the changes in thyroid hormone concentrations were reversible. In all 10 patients with a low uptake, however, the values were irreversible.

Among the reversible group five patients had a history of habitual ingestion of seaweed. The perchlorate test performed in two of these five showed a significant discharge of the radioactive iodine from the thyroid glands. The other nine patients in the group had no history of habitual ingestion of excessive iodide, and in five of them the perchlorate discharge test gave negative results. With their consent two of the patients were loaded with excess iodide; neither became hypothyroid again, and they were considered to be iodide insensitive.

Two of the 14 patients in the reversible group complained only of recent swelling of the neck, but the other 12 patients showed typical signs and symptoms of hypothyroidism, which improved after spontaneous recovery of thyroid function.

\section{Discussion}

Primary hypothyroidism is related to Hashimoto's thyroiditis, iodine deficiency, dyshormonogenesis, surgery or treatment with radioactive iodine for Graves' disease or thyroid cancer, or ingestion of a goitrogen. Hypothyroidism is sometimes transient or reversible, ${ }^{1-8}$ but reversible hypothyroidism is thought to be rare and has not been emphasised in most of the textbooks. ${ }^{9-12}$

In over half of the patients in the present study the serum thyroid hormone concentrations began to increase without replacement therapy, and 10 of the 27 patients became euthyroid within three months. This is particularly remarkable since patients with apparent postpartum hypothyroidism and those with primary hypothyroidism with only slightly raised serum TSH concentrations (10-40 mU/1) were excluded from the study.

It was also surprising to find such a high incidence of goitre in these patients with primary hypothyroidism. A previous report found only $5 \%$ of patients with myxoedema, excluding those who had undergone thyroidectomy. ${ }^{13}$ The increase in incidence may have been due to the recent increase in the incidence of chronic thyroiditis. ${ }^{14}$ The incidence of goitre also depends on the geographical location. The average diet in Japan is rich in iodine and this may be partly responsible for the high incidence of reversible hypothyroidism. In the Western world, however, the content of iodide in foods and drugs is increasing ${ }^{15}$ and the normal range of thyroid uptake of iodine is being lowered. ${ }^{16}$

It is reasonable that most of the hypothyroid patients with goitres and with high uptakes of iodine showed spontaneous improvement, while those without goitres and with low iodine uptakes required replacement treatment. If there remain thyroid cells which can concentrate iodide the thyroid has a chance of regaining normal function after the removal of some inhibitory factor(s) of the hormone synthesis. On the other hand, if the thyroid gland is atrophic spontaneous recovery will not occur.

It is difficult to show which step of thyroid hormone synthesis or secretion is reversibly inhibited. A positive perchlorate test result in the patients with a history of seaweed ingestion suggested that, at least in these patients, organification of iodide was reversibly inhibited by excess iodide, as shown previously in Hashimoto's thyroiditis. ${ }^{4}$

To classify primary hypothyroidism as reversible or irreversible, we recommend that clinicians should wait for a few days before starting replacement therapy to see whether thyroid function spontaneously returns to normal with only iodine restriction. If the patient has a goitre with a high uptake of iodine and the serum concentration of TSH tends to decline then he or she should be further followed up for an additional few weeks without replacement therapy, in the expectation that there will be a spontaneous and gradual recovery.

We thank Ms Kumiko Sunabe for her expert secretarial help and Ms Mariko Ohara for help in preparing the manuscript.

\section{References}

${ }^{1}$ Amino N, Miyai K, Kuro R, et al. Transient postpartum hypothyroidism: fourteen cases with autoimmune thyroiditis. Ann Intern Med 1977;87: 155-9.

${ }^{2}$ Amino N, Mori H, Iwatani Y, et al. High prevalence of transient postpartum thyrotoxicosis and hypothyroidism. N Engl f Med 1982;306: 849-52.

${ }^{3}$ Braverman LE, Ingbar SH, Vagenakis AG, Adams L, Maloof F. Enhanced susceptibility to iodide myxedema in patients with Hashimoto's disease. f Clin Endocrinol Metab 1971;32:515-21.

- Okamura K, Inoue K, Omae T. A case of Hashimoto's thyroiditis with thyroidal immunological abnormality manifested after habitual ingestion of seaweed. Acta Endocrinol (Copenhagen) 1978;88:703-12.

${ }^{5}$ Rallison ML, Dobyns BM, Keating FR, Rall JE, Tyler FH. Occurrence and natural history of chronic lymphocytic thyroiditis in childhood. $f$ Pediatr $1975 ; 86: 675-82$.

- Yamamoto T, Sakamoto H. Spontaneous remission from primary hypothyroidism. Ann Intern Med 1978;88:808-9.

7 Carlson HE. Spontaneous remission of hypothyroidism. Arch Intern Med $1980 ; 140: 1675-6$

${ }^{8}$ How J, Khir ASM, Bewsher PF. Spontaneous remission of hypothyroidism due to Hashimoto's thyroiditis. Lancet 1980;ii :427.

- DeGroot LJ, Stanbury JB. Adult hypothyroid states and myxedema. In DeGroot LJ, Stanbury JB, eds. The thyroid and its disease. 4th ed. New York: John Wiley and Sons Inc, 1975;405-71.

10 Werner SC. Hypothyroidism. In: Werner SC, Ingbar SH, eds. The thyroid. 4th ed. Hagerstown: Harper \& Row Publishers Inc, 1978: 843-974.

11 Utiger RD. Hypothyroidism. In: DeGroot LJ, Cahill GF Jr, Odell WD, et al, eds. Endocrinology. Vol 1. New York: Grune and Stratton, 1979: 471-88.

${ }^{12}$ De Visscher M, Ingenbleek Y. Hypothyroidism. In: De Visscher M, ed. Comprehensive endocrinology: the thyroid gland. New York: Raven Press, 1980:377-412.

13 Watanakunakorn C, Hodges RE, Evans TC. Myxedema. A study of 400 cases. Arch Intern Med 1965;116:183-90.

14 Weaver DK, Nishiyama RH, Burton WD, Batsakis JG. Surgical thyroid disease: a survey before and after iodine prophylaxis. Arch Surg 1966; 92:796-801.

15 Oddie TH, Fisher DA, McConahey WM, Thompson CS. Iodine intake in the United States: a reassessment. $\mathcal{F}$ Clin Endocrinol Metab 1970;30 659-65.

${ }^{16}$ Pittman JA, Dailey GE, Beschi RJ. Changing normal values for thyroidal radioiodine uptake. $N$ Engl f Med 1969;280:1431-4.

(Accepted 17 fune 1983)
NICORIMI Tobacco. It is hot and dry in the second degree, and of a cleansing nature: the leaves warmed and applied to the head, are excellently good in inveterate head-aches and megrims, if the diseases come through cold or wind, change them often till the diseases be gone, help such whose necks be stiff: it eases the faults of the breast: Asthma's or head-flegm in the lappets of the lungs: eases the pains of the stomach and windiness thereof: being heated by the fire, and applied hot to the side, they loosen the belly, and kill worms being applied unto it in like manner: they break the stone being applied in like manner to the region of the bladder: help the rickets, being applied to the belly and sides: applied to the navel, they give present ease to the fits of the mother: they take away cold aches in the joints applied to them: boiled, the liquor absolutely and speedily cures scabs and itch: neither is there any better salve in the world for wounds than may be made of it: for it cleanses, fetches out the filth though it lie in the bones, brings up the flesh from the bottom, and all this it doth speedily: it cures wounds made with poisoned weapons, and for this CLUSIUS brings many experiences too tedious here to relate. It is an admirable thing for carbuncles and plague-sores, inferior to none: green wounds 'twill cure in a trice: ulcers and gangreens very speedily, not only in men, but also in beasts, therefore the Indians dedicated it to their god. Taken in a pipe, it hath almost as many virtues; it easeth weariness, takes away the sense of hunger and thirst, provokes to stool: the Indians will travel four days without either meat or drink, by only chewing a little of this in their mouths: It eases the body of superfluous humours, opens stoppings. (Nicholas Culpeper (1616-54) The Complete Herbal, 1850.) 